\title{
50MEKANISME SERTIFIKASI TENAGA AHLI JASA KONSTRUKSI MENURUT UNDANG-UNDANG NOMOR 11 TAHUN 2014 TENTANG KEINSINYURAN
}

\author{
Irika Widiasanti
}

\begin{abstract}
Abstrak
Undang-undang nomor 11 tahun 2014 tentang Keinsinyuran disahkan 25 Pebruari 2014 bertujuan untuk mencegah kesalahan dan kelalaian praktek keinsinyuran yang dapat merugikan masyarakat, mengatasi pekerjaan teknologi dan ahli teknologi, mengamankan investasi, dan anggaran pembangunan, mengembangkan keinsinyuran dan teknologi serta penyetaraan kualifikasi dan kompetensi insinyur Indonesia dengan insinyur dari negara lain. Sehinnga nantinya mampu memajukan profesi keinsinyuran agar menjadi ujung tombak pembangunan dan daya saing global untuk kemajuan dan kesejahteraan bangsa Indonesia. Kesiapan lulusan teknik untuk bersaing di pasar harus dibarengi dengan aturan hukum dan perundangan yang mengaturnya. Selain itu, UU Keinsinyuran juga mengatur tentang sertifikasi insinyur professional, penyelenggaraan lisensi kerja hingga standar pelayanan. Hal-hal yang mendorong penyelenggaraan sertifikasi tenaga kerja konstruksi antara lain adalah segmentasi pasar kerja bergeser dari pendekatan wilayah ke pendekatan profesi dan kompetensi , Sumber Daya Manusia kompetensi tinggi untuk memenangkan persaingan, sertifikat menjadi bukti pengakuan kualifikasi tertulis.
\end{abstract}

Studi ini bertujuan untuk mengetahui mekanisme sertifikasi tenaga ahli jasa konstruksi sebagai salah satu bidang keinsinyuran yang diatur pada UU Keinsinyuran ini. Pembahasan ditinjau terhadap lembaga penyelenggara dan proses penyelenggaraan.

Pelaksanaan studi mengacu pada metodologi yang meliputi kegiatan utama Studi literatur, pengumpulan data primer dan sekunder, analisis data, perumusan kesimpulan dan rekomendasi. Analisis dilakukan didasarkan pada informasi yang diperolah dari berbagai sumber, baik informasi sekunder, informasi primer yang dilengkapi dengan pendapat para pakar dan praktisi.

Hasil dari studi ini, diharapkan dapat memperkuat konsep sertifikasi tenaga ahli sesuai dengan prinsip sistem nilai dan base practice internasional

Kata kunci: undang-undang keinsinyuran, sertifikasi tenaga ahli jasa konstruksi 


\section{PENDAHULUAN}

Sumber daya manusia yang mampu melakukan rekayasa teknik masih tersebar dalam berbagai profesi dan kelembagaan masing-masing, belum mempunyai standar keahlian, kemampuan, dan kompetensi Insinyur. Insinyur sebagai salah satu komponen utama yang melakukan layanan jasa rekayasa teknik harus memiliki kompetensi untuk melakukan pekerjaan secara profesional sehingga kegiatan yang dilakukannya dapat meningkatkan kualitas hidup masyarakat dan dirinya. Hasil karya Insinyur harus dapat dipertanggungjawabkan, baik secara moril-materiil maupun di muka hukum sehingga layanan jasa di bidang Keinsinyuran memiliki kepastian hukum, memberikan pelindungan bagi Insinyur dan pengguna, serta dilakukan secara profesional, bertanggung jawab, dan menjunjung tinggi etika profesi.

Unsur penting dalam Praktik Keinsinyuran adalah sikap, penguasaan ilmu pengetahuan, teknologi, dan keterampilan teknik yang dimiliki, yang diperoleh melalui pendidikan dan pelatihan. Pengetahuan yang dimiliki Insinyur harus terus-menerus dipertahankan dan ditingkatkan sesuai dengan kemajuan ilmu pengetahuan dan teknologi, serta kebutuhan industri. Perangkat keilmuan yang dimiliki seorang Insinyur mempunyai karakteristik yang khas yang terlihat dari kemampuan untuk melakukan upaya rekayasa teknik yang sesuai dengan kebutuhan dan karakteristik lingkungan serta menyesuaikan dengan perkembangan teknologi yang ada.

Pengaturan Praktik Keinsinyuran dilakukan untuk memberikan landasan dan kepastian hukum serta pelindungan kepada Pengguna Keinsinyuran dan Pemanfaat Keinsinyuran. Pengaturan Praktik Keinsinyuran dimaksudkan juga untuk memberikan arah pertumbuhan dan peningkatan profesionalisme Insinyur, meletakkan Keinsinyuran Indonesia pada peran dalam pembangunan nasional, serta menjamin terwujudnya penyelenggaraan Keinsinyuran Indonesia yang baik. Oleh karena itu, Praktik Keinsinyuran perlu diatur dalam suatu peraturan perundang-undangan guna memberikan kepastian dan pelindungan hukum kepada Insinyur, Pengguna Keinsinyuran, dan Pemanfaat Keinsinyuran. Hal tersebut dilakukan untuk meningkatkan keselamatan kerja, keberlanjutan lingkungan, dan keunggulan hasil rekayasa, untuk meningkatkan kualitas hidup, serta kesejahteraan Insinyur dan masyarakat.

Rancangan Undang-Undang Keinsinyuran akhirnya disahkan menjadi Undang-Undang dalam sidang paripurna di Gedung Parlemen, Jakarta, Selasa 25 Pebruari 2014 menjadi Undang- 
Undang Republik Indonesia nomor 11 tahun 2014 tentang Keinsinyuran. UU Keinsinyuran sangat tepat dan ditunggu oleh kalangan insinyur serta profesional untuk melindungi kesetaraan di kancah global. Diharapkan UU ini dapat menjaga profesionalitas insinyur Indonesia yang berdaya saing internasional. (Nuh M. , 2014).

UU Keinsinyuran dibuat dengan tujuan untuk mencegah kesalahan dan kelalaian praktek keinsinyuran yang dapat merugikan masyarakat, mengatasi pekerjaan teknologi dan ahli teknologi, mengamankan investasi, dan anggaran pembangunan, mengembangkan keinsinyuran dan teknologi serta penyetaraan kualifikasi dan kompetensi insinyur Indonesia dengan insinyur dari negara lain. (Mulyono, 2012). Sehinnga nantinya mampu memajukan profesi keinsinyuran agar menjadi ujung tombak pembangunan dan daya saing global untuk kemajuan dan kesejahteraan bangsa Indonesia. Kesiapan lulusan teknik untuk bersaing di pasar harus dibarengi dengan aturan hukum dan perundangan yang mengaturnya. UU Keinsinyuran akan melindungi konsumen pengguna jasa profesi insinyur, sekaligus menjaga kualitas dan kompetensi profesi insinyur yang bekerja di Indonesia. Selain itu, UU Keinsinyuran juga akan mengatur tentang sertifikasi insinyur professional, penyelenggaraan lisensi kerja hingga standar pelayanan.

UU Keinsinyuran yang terdiri dari $15 \mathrm{BAB}$ dan 54 pasal, membuka peluang bagi selain sarjana teknik untuk mencapai kompetensi insinyur dan berprofesi sebagai insinyur. UU ini menganut sistem terbuka untuk profesi keinsinyuran, dengan memperhatikan pengalaman profesi seseorang. Sistem ini menekankan agar para insinyur selalu mengembangkan keprofesionalannya dengan belajar terus-menerus serta melaksanakan darma bakti keinsinyuran kepada masyarakat. (Nuh M. , 2014).

\section{PEMBAHASAN}

Lingkup pengaturan Undang-Undang tentang Keinsinyuran adalah cakupan Keinsinyuran, standar Keinsinyuran, Program Profesi Insinyur, Registrasi Insinyur, Insinyur asing, Pengembangan Keprofesian Berkelanjutan, hak dan kewajiban, kelembagaan Insinyur, organisasi profesi Insinyur, dan pembinaan Keinsinyuran. Undang-Undang ini mengatur bahwa Keinsinyuran mencakup disiplin teknik Keinsinyuran dan bidang Keinsinyuran. Sementara itu, untuk menjamin mutu kompetensi dan profesionalitas layanan profesi Insinyur, dikembangkan 
standar profesi Keinsinyuran yang terdiri atas standar layanan Insinyur, standar kompetensi Insinyur, dan standar Program Profesi Insinyur.

Dalam Undang-Undang ini diatur pula bahwa setiap Insinyur yang melakukan praktik Keinsinyuran harus memiliki Surat Tanda Registrasi Insinyur yang dikeluarkan oleh PII dan berlaku selama 5 (lima) tahun serta diregistrasi ulang setiap 5 (lima) tahun. Selain itu, diatur bahwa Insinyur Asing yang melakukan Praktik Keinsinyuran di Indonesia harus memiliki surat izin kerja tenaga kerja asing sesuai dengan ketentuan peraturan perundang-undangan dan memenuhi ketentuan dalam Undang-Undang ini.

Dalam rangka meningkatkan profesionalitas profesi Insinyur, diselenggarakan Pengembangan Keprofesian Berkelanjutan yang bertujuan untuk memelihara kompetensi dan profesionalitas Insinyur dan mengembangkan tanggung jawab sosial Insinyur pada lingkungan profesinya dan masyarakat di sekitarnya.

Kelembagaan Keinsinyuran terdiri atas 2 (dua) lembaga, yaitu Dewan Insinyur Indonesia dan Persatuan Insinyur Indonesia (PII). Dewan Insinyur Indonesia mempunyai fungsi merumuskan kebijakan penyelenggaraan dan pengawasan pelaksanaan Praktik Keinsinyuran, sementara itu, PII merupakan lembaga yang berfungsi melaksanaan Praktik Keinsinyuran. Pembinaan Praktik Keinsinyuran merupakan tanggung jawab Pemerintah yang dilakukan oleh menteri yang menyelenggarakan urusan pemerintahan di bidang pendidikan dan menteri lainnya yang terkait.

Undang-undang ini juga mengatur ketentuan peralihan guna memberikan kepastian hukum terkait dengan kenyataan bahwa kegiatan Keinsinyuran telah lama dipraktikkan dalam masyarakat sebelum lahirnya undang-undang ini, terutama mengenai pengakuan dan status Insinyur yang sudah bekerja secara profesional di bidang Keinsinyuran sebelum lahirnya Undang-undang ini.

Dengan Undang-undang ini juga diharapkan keinsinyuran dapat meningkatkan daya saing bangsa dan negara dalam menggali dan memberikan nilai tambah atas berbagai potensi yang dimiliki tanah air, menjawab kebutuhan mengatasi segala kendala dan masalah dari perubahan 
global yang dihadapi dan selanjutnya dapat menyumbang banyak bagi kemajuan dan kemandirian bangsa.

Berikut ini adalah pasal-pasal dalam UU Keinsinyuran terkait dengan penyelenggaraan sertifikasi tenaga ahli konstruksi.

Tabel 1. Pasal-pasal dalam UU 11 tahun 2014 tentang Keinsinyuran terkait mekanisme Sertifikasi Tenaga Ahli Jasa Konstruks

\begin{tabular}{|c|c|c|c|}
\hline No & Pasal & Tentang & Uraian \\
\hline 1. & $5: 1 b$ & cakupan & Disiplin teknik : Rekayasa sipil dan lingkungan terbangun \\
\hline 2. & $5: 2 c$ & cakupan & Bidang : Konsultasi, rancang bangun, dan konstruksi \\
\hline 3. & $5: 3$ & cakupan & $\begin{array}{l}\text { Cakupan disiplin \& cakupan bidang keinsinyuran diatur dalam } \\
\text { Peraturan Pemerintah }\end{array}$ \\
\hline 4. & $6: 1$ & standar & $\begin{array}{l}\text { Standar profesi Keinsinyuran yang terdiri atas: } \\
\text { a. standar layanan Insinyur; } \\
\text { b. standar kompetensi Insinyur; dan } \\
\text { c. standar Program Profesi Insinyur. }\end{array}$ \\
\hline 5. & $6: 2$ & standar & $\begin{array}{l}\text { Standar layanan Insinyur ditetapkan oleh menteri yang } \\
\text { membina bidang Keinsinyuran atas usul PII. }\end{array}$ \\
\hline 6. & $6: 3$ & standar & $\begin{array}{l}\text { Standar kompetensi Insinyur ditetapkan oleh Dewan Insinyur } \\
\text { Indonesia bersama menteri yang membina bidang } \\
\text { Keinsinyuran. }\end{array}$ \\
\hline 7. & $6: 4$ & standar & $\begin{array}{l}\text { Standar Program Profesi Insinyur ditetapkan oleh Menteri } \\
\text { yang disusun atas usul perguruan tinggi penyelenggara } \\
\text { Program Profesi Insinyur bersama dengan menteri yang } \\
\text { membina bidang Keinsinyuran dan Dewan Insinyur Indonesia }\end{array}$ \\
\hline 8. & $7: 1$ & $\begin{array}{l}\text { Program } \\
\text { Profesi Insinyur } \\
\text { (PPI) }\end{array}$ & $\begin{array}{l}\text { Untuk memperoleh gelar profesi Insinyur, seseorang harus } \\
\text { lulus dari Program Profesi Insinyur }\end{array}$ \\
\hline 9. & $7: 2$ & Syarat PPI & $\begin{array}{l}\text { Syarat untuk dapat mengikuti Program Profesi Insinyur } \\
\text { sebagaimana dimaksud pada ayat (1) meliputi: } \\
\text { a. sarjana bidang teknik atau sarjana terapan bidang teknik, } \\
\text { baik lulusan perguruan tinggi dalam negeri maupun } \\
\text { perguruan tinggi luar negeri yang telah disetarakan; atau } \\
\text { b. sarjana pendidikan bidang teknik atau sarjana bidang } \\
\text { sains yang disetarakan dengan sarjana bidang teknik atau } \\
\text { sarjana terapan bidang teknik melalui program }\end{array}$ \\
\hline
\end{tabular}


Tabel 1. Pasal-pasal dalam UU 11 tahun 2014 tentang Keinsinyuran terkait mekanisme Sertifikasi Tenaga Ahli Jasa Konstruks

\begin{tabular}{|c|c|c|c|}
\hline No & Pasal & Tentang & Uraian \\
\hline & & & penyetaraan. \\
\hline 10. & $7: 3$ & Syarat PPI & $\begin{array}{l}\text { Program Profesi Insinyur dapat diselenggarakan melalui } \\
\text { mekanisme rekognisi pembelajaran lampau. }\end{array}$ \\
\hline 11. & $8: 1$ & $\begin{array}{l}\text { Penyelenggara } \\
\text { PPI }\end{array}$ & $\begin{array}{l}\text { Program Profesi Insinyur diselenggarakan oleh perguruan } \\
\text { tinggi bekerja sama dengan kementerian terkait, PII, dan } \\
\text { kalangan industri dengan mengikuti standar Program Profesi } \\
\text { Insinyur sebagaimana dimaksud dalam Pasal } 6 \text { ayat (4). }\end{array}$ \\
\hline 12. & $8: 2$ & $\begin{array}{l}\text { sertifikat profesi } \\
\text { Insinyur }\end{array}$ & $\begin{array}{l}\text { Seseorang yang telah memenuhi standar Program Profesi } \\
\text { Insinyur, baik melalui program profesi maupun melalui } \\
\text { mekanisme rekognisi pembelajaran lampau, serta lulus } \\
\text { Program Profesi Insinyur berhak mendapatkan sertifikat } \\
\text { profesi Insinyur dan dicatat oleh PII. }\end{array}$ \\
\hline 13. & $8: 3$ & $\begin{array}{l}\text { Penyelenggara } \\
\text { PPI }\end{array}$ & $\begin{array}{l}\text { Ketentuan lebih lanjut mengenai Program Profesi Insinyur } \\
\text { diatur dalam Peraturan Pemerintah }\end{array}$ \\
\hline 14. & $9: 1$ & gelar "Ir." & $\begin{array}{l}\text { Gelar profesi Insinyur sebagaimana dimaksud dalam Pasal } 7 \\
\text { ayat (1) disingkat dengan "Ir." dan dicantumkan di depan nama } \\
\text { yang berhak menyandangnya }\end{array}$ \\
\hline 15. & $9: 2$ & gelar "Ir." & $\begin{array}{l}\text { Gelar profesi Insinyur sebagaimana dimaksud pada ayat (1) } \\
\text { diberikan oleh perguruan tinggi penyelenggara Program } \\
\text { Profesi Insinyur yang bekerja sama dengan kementerian } \\
\text { terkait dan PII. }\end{array}$ \\
\hline 16. & $10: 1$ & registrasi & $\begin{array}{l}\text { Setiap Insinyur yang akan melakukan Praktik Keinsinyuran di } \\
\text { Indonesia harus memiliki Surat Tanda Registrasi Insinyur }\end{array}$ \\
\hline 17. & $10: 2$ & registrasi & $\begin{array}{l}\text { Surat Tanda Registrasi Insinyur sebagaimana dimaksud pada } \\
\text { ayat (1) dikeluarkan oleh PII. }\end{array}$ \\
\hline 18. & $11: 1$ & $\begin{array}{l}\text { Sertifikat } \\
\text { Kompetensi } \\
\text { Insinyur }\end{array}$ & $\begin{array}{l}\text { Untuk memperoleh Surat Tanda Registrasi Insinyur } \\
\text { sebagaimana dimaksud dalam Pasal } 10 \text {, seorang Insinyur } \\
\text { harus memiliki Sertifikat Kompetensi Insinyur. }\end{array}$ \\
\hline 19. & $11: 2$ & $\begin{array}{l}\text { Sertifikat } \\
\text { Kompetensi } \\
\text { Insinyur }\end{array}$ & $\begin{array}{l}\text { Sertifikat Kompetensi Insinyur sebagaimana dimaksud pada } \\
\text { ayat (1) diperoleh setelah lulus Uji Kompetensi. }\end{array}$ \\
\hline 20. & $11: 3$ & $\begin{array}{l}\text { Sertifikat } \\
\text { Kompetensi } \\
\text { Insinyur }\end{array}$ & $\begin{array}{l}\text { Uji Kompetensi sebagaimana dimaksud pada ayat (2) } \\
\text { dilakukan oleh lembaga sertifikasi profesi sesuai dengan } \\
\text { ketentuan peraturan perundang-undangan }\end{array}$ \\
\hline 21. & 12 & Tanda & Surat Tanda Registrasi Insinyur paling sedikit mencantumkan: \\
\hline
\end{tabular}


Tabel 1. Pasal-pasal dalam UU 11 tahun 2014 tentang Keinsinyuran terkait mekanisme Sertifikasi Tenaga Ahli Jasa Konstruks

\begin{tabular}{|c|c|c|c|}
\hline No & Pasal & Tentang & Uraian \\
\hline & & $\begin{array}{l}\text { Registrasi } \\
\text { Insinyur }\end{array}$ & $\begin{array}{l}\text { a. jenjang kualifikasi profesi; dan } \\
\text { b. masa berlaku }\end{array}$ \\
\hline 22. & 13 & $\begin{array}{l}\text { Surat Tanda } \\
\text { Registrasi } \\
\text { Insinyur }\end{array}$ & $\begin{array}{l}\text { Surat Tanda Registrasi Insinyur berlaku selama } 5 \text { (lima) tahur } \\
\text { dan diregistrasi ulang setiap } 5 \text { (lima) tahun dengan tetap } \\
\text { memenuhi persyaratan sebagaimana dimaksud dalam Pasa } \\
11 \text { dan persyaratan Pengembangan Keprofesiar } \\
\text { Berkelanjutan. }\end{array}$ \\
\hline 23. & $18: 2$ & Insinyur Asing & $\begin{array}{l}\text { harus memiliki surat izin kerja tenaga kerja asing ses } \\
\text { dengan ketentuan peraturan perundang-undangan. }\end{array}$ \\
\hline 24. & $18: 3$ & Insinyur Asing & $\begin{array}{l}\text { Untuk mendapat surat izin kerja sebagaimana dimaksud pa } \\
\text { ayat (2), Insinyur Asing harus memiliki Surat Tanda Registr } \\
\text { Insinyur dari PII berdasarkan surat tanda registrasi at } \\
\text { sertifikat kompetensi Insinyur menurut hukum negaranya. }\end{array}$ \\
\hline 25. & $18: 4$ & Insinyur Asing & $\begin{array}{l}\text { Dalam hal Insinyur Asing tidak memiliki surat tanda registras } \\
\text { atau sertifikat kompetensi Insinyur menurut hukum negaranya } \\
\text { sebagaimana dimaksud pada ayat (3), Insinyur Asing harus } \\
\text { memenuhi syarat sebagaimana dimaksud dalam Pasal } 11 .\end{array}$ \\
\hline 26. & 20 & Insinyur Asing & $\begin{array}{l}\text { Insinyur Asing yang memberikan jasa Keinsinyuran dal } \\
\text { penanganan bencana atau konsultasi yang bersifat insider } \\
\text { tidak memerlukan surat izin kerja, tetapi ha } \\
\text { memberitahukan kepada kementerian terkait. }\end{array}$ \\
\hline 27. & $23: 1$ & $\begin{array}{l}\text { Pengembangan } \\
\text { Keprofesian } \\
\text { Berkelanjutan }\end{array}$ & $\begin{array}{l}\text { bertujuan: } \\
\text { memelihara kompetensi dan profesionalitas Insinyur; dan } \\
\text { mengembangkan tanggung jawab sosial Insinyur pc } \\
\text { lingkungan profesinya dan masyarakat di sekitarnya. }\end{array}$ \\
\hline 28. & $23: 2$ & $\begin{array}{l}\text { Pengembangan } \\
\text { Keprofesian } \\
\text { Berkelanjutan }\end{array}$ & $\begin{array}{l}\text { diselenggarakan oleh PII dan dapat bekerja sama deng } \\
\text { lembaga pelatihan dan pengembangan profesi. }\end{array}$ \\
\hline 29. & $23: 3$ & $\begin{array}{l}\text { Pengembangan } \\
\text { Keprofesian } \\
\text { Berkelanjutan }\end{array}$ & $\begin{array}{l}\text { Standar disusun dan ditetapkan oleh Dewan Insinyu } \\
\text { Indonesia sesuai dengan perkembangan kemajuan ilm } \\
\text { pengetahuan dan teknologi. }\end{array}$ \\
\hline 30. & $23: 4$ & $\begin{array}{l}\text { Pengembangan } \\
\text { Keprofesian } \\
\text { Berkelanjutan }\end{array}$ & $\begin{array}{l}\text { merupakan syarat untuk perpanjangan Surat Tanda Registras } \\
\text { Insinyur. }\end{array}$ \\
\hline
\end{tabular}

31. $23: 5$ Pengembangan PII melakukan pemantauan dan penilaian atas pelaksanaan 
Tabel 1. Pasal-pasal dalam UU 11 tahun 2014 tentang Keinsinyuran terkait mekanisme Sertifikasi Tenaga Ahli Jasa Konstruks

\begin{tabular}{|c|c|c|c|}
\hline No & Pasal & Tentang & Uraian \\
\hline & & $\begin{array}{l}\text { Keprofesian } \\
\text { Berkelanjutan }\end{array}$ & Pengembangan Keprofesian Berkelanjutan \\
\hline 32. & $30: 2$ & $\begin{array}{l}\text { Dewan Insinyur } \\
\text { Indonesia }\end{array}$ & bertanggung jawab kepada Presiden. \\
\hline 33. & $30: 3$ & $\begin{array}{l}\text { Dewan Insinyur } \\
\text { Indonesia }\end{array}$ & berkedudukan di ibu kota Negara Republik Indonesia. \\
\hline 34. & $30: 4$ & $\begin{array}{l}\text { Dewan Insinyur } \\
\text { Indonesia }\end{array}$ & $\begin{array}{l}\text { Dewan Insinyur Indonesia beranggotakan paling sedikit } 5 \\
\text { (lima) orang yang terdiri atas unsur: } \\
\text { a. Pemerintah; } \\
\text { b. industri; } \\
\text { c. perguruan tinggi; } \\
\text { d. PII; dan } \\
\text { e. Pemanfaat Keinsinyuran. }\end{array}$ \\
\hline 35. & $30: 5$ & $\begin{array}{l}\text { Dewan Insinyur } \\
\text { Indonesia }\end{array}$ & $\begin{array}{l}\text { Keanggotaan Dewan Insinyur Indonesia ditetapkan oleh } \\
\text { Presiden atas usul Menteri. }\end{array}$ \\
\hline 36. & $30: 6$ & $\begin{array}{l}\text { Dewan Insinyur } \\
\text { Indonesia }\end{array}$ & $\begin{array}{l}\text { Keanggotaan Dewan Insinyur Indonesia sebagaimana } \\
\text { dimaksud pada ayat (5) berlaku selama } 5 \text { (lima) tahun dan } \\
\text { dapat diangkat kembali untuk } 1 \text { (satu) kali masa jabatan } \\
\text { berikutnya. }\end{array}$ \\
\hline 37. & 32 & $\begin{array}{l}\text { Dewan Insinyur } \\
\text { Indonesia }\end{array}$ & $\begin{array}{l}\text { Dewan Insinyur Indonesia mempunyai tugas: } \\
\text { a. menetapkan kebijakan sistem registrasi Insinyur; } \\
\text { b. mengusulkan standar Program Profesi Insinyur; } \\
\text { c. menetapkan standar Pengembangan Keprofesian } \\
\text { Berkelanjutan; } \\
\text { d. melakukan pengawasan pelaksanaan Praktik Keinsinyuran } \\
\text { oleh PII; } \\
\text { e. menetapkan kebijakan sistem Uji Kompetensi; } \\
\text { f. menetapkan standar kompetensi Insinyur; }\end{array}$ \\
\hline 38. & 33 & $\begin{array}{l}\text { Dewan Insinyur } \\
\text { Indonesia }\end{array}$ & $\begin{array}{l}\text { wewenang: } \\
\text { a. mengesahkan sistem registrasi Insinyur; } \\
\text { b. mengesahkan sistem Uji Kompetensi; } \\
\text { c. melakukan pencatatan terhadap Insinyur yang dikenai } \\
\text { sanksi karena melanggar ketentuan kode etik Insinyur; } \\
\text { dan }\end{array}$ \\
\hline
\end{tabular}


Tabel 1. Pasal-pasal dalam UU 11 tahun 2014 tentang Keinsinyuran terkait mekanisme Sertifikasi Tenaga Ahli Jasa Konstruks

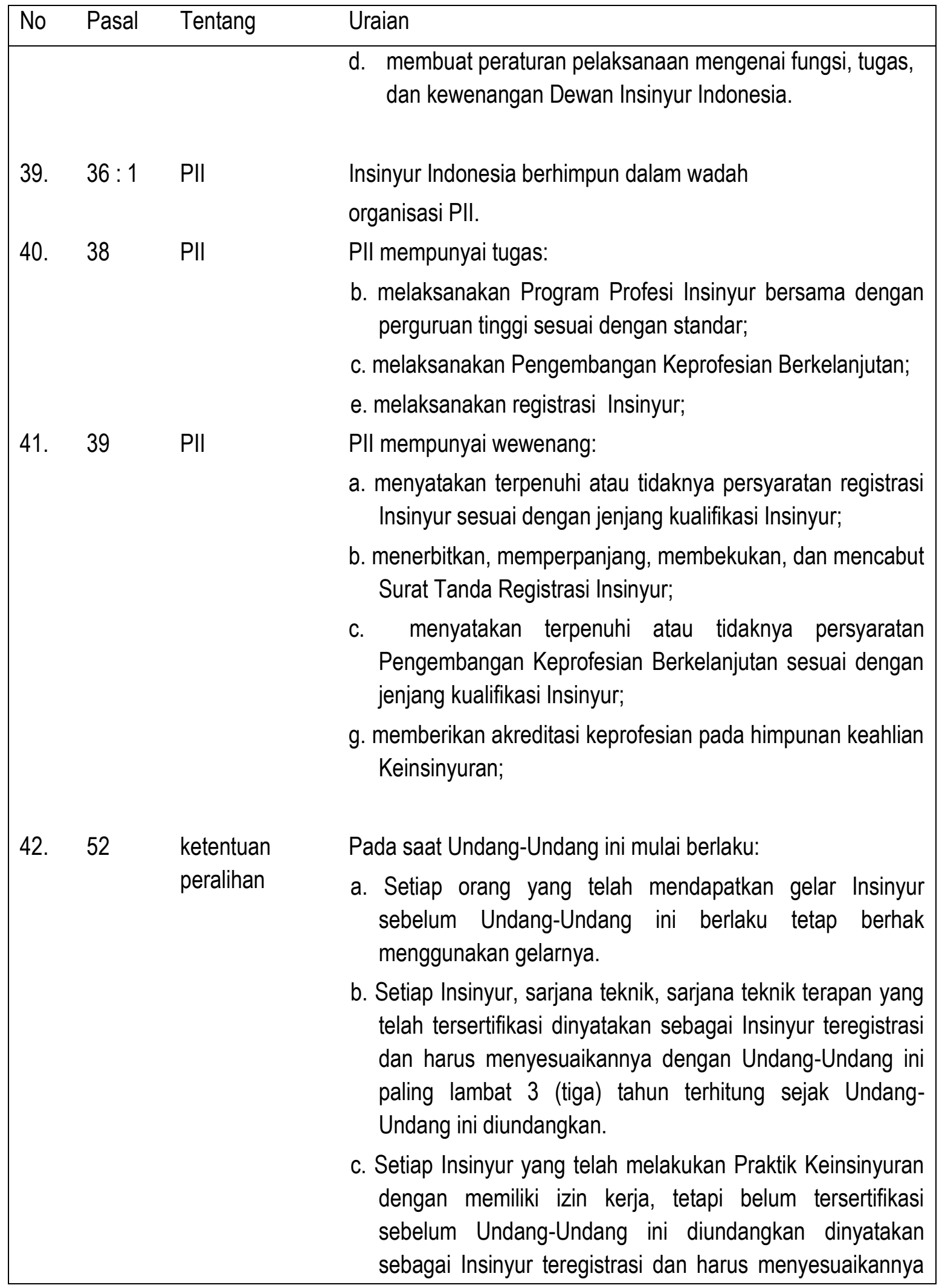


Tabel 1. Pasal-pasal dalam UU 11 tahun 2014 tentang Keinsinyuran terkait mekanisme Sertifikasi Tenaga Ahli Jasa Konstruks

\begin{tabular}{|c|c|c|}
\hline Pasal & Tentang & Uraian \\
\hline & & $\begin{array}{l}\text { dengan Undang-Undang ini paling lambat } 3 \text { (tiga) tahun } \\
\text { terhitung sejak Undang-Undang ini diundangkan. }\end{array}$ \\
\hline
\end{tabular}

\section{PENUTUP}

Hal-hal yang perlu diperhatikan terkait dengan mekanisme sertifikasi tenaga ahli yang diatur dalam UU 11 tahun 2014 :

1. Tenaga ahli setelah lulus Program Profesi Insinyur mendapatkan sertifikat profesi insinyur dan dicatat di PII (8:2) serta berhak memakai gelar "Ir" (9:1). Tetapi belum dianggap kompeten (11:2) dan belum dapat melakukan Praktik Keinsinyuran (10:1)

2. Registrasi Insinyur sebagai syarat untuk melakukan Praktik Insinyur (10:1) dikeluarkan oleh PII (10:2) sedangkan PII adalah organisasi (36:1)

3. Uji kompetensi sebagai cara pembuktian tertulis kompetensi insinyur (11:2) dilakukan oleh lembaga sertifikasi profesi sesuai dengan ketentuan perundang-undangan (11:3). Hal ini dapat diartikan bahwa lembaga yang menyelenggarakan uji kompetensi diatur oleh Peraturan Pemerintah Nomor 23 Tahun 2004 Tentang Badan Nasional Sertifikasi Profesi (BNSP). BNSP mempunyai tugas melaksanakan sertifikasi kompetensi kerja. (PP 23/2004 pasal 3), lebih cenderung untuk kegiatan tenaga kerja trampil.

4. Pembentukan Dewan Insinyur dengan tugas dan kewenangannya (pasal 32, 33), akan menjadi kompleks untuk diterapkan pada masing-masing cakupan 7 disiplin teknik (5:1b).

5. Tantangan memfungsikan PII sebagai pelaksanaan registrasi sertifikasi, terkait

a. Dukungan professional

b. Pendanaan .

6. Pengembangan profesi berkelanjutan, dipantau oleh PII (23:5). Belum diatur lebih lanjut, institusi yang melaksanakan.

7. Disarankan, uji kompentensi dilakukan bersamaan dengan uji Program Profesi Insinyur. 


\section{DAFTAR PUSTAKA}

Arifin, D. Z. (2010). Evaluasi Kebijakan Sertifikasi Tenaga Ahli Konstruksi di Lembaga Pengembangan Jasa Konstruksi (LPJK), Disertasi. Program Pascasarjana Universitas Negeri Jakarta.

Marhayudi, P. (2013). Isu-isu Aktual Terkait Kebijakan \& Pengaturan Jasa Konstruksi dalam Menunjang Implementasi MP3I. Seminar Nasional ITS, 6 Pebruari 2013. Surabaya.

Mulyono, I. (2012, Juni 27). RUU Keinsinyuran Diharap Perbaiki Kompetensi Insinyur. Retrieved 4 20, 2014, from Dewan Perwakilan Rakyat Republik Indonesia: http://www.dpr.go.id/id/berita/baleg/2012/jun/27/4144/ruu-keinsinyuran-diharap-perbaikikompetensi-insinyur

Nuh, M. (2014, Pebruari 25). Disahkan, Undang-undang Keinsinyuran untuk Lindungi Insinyur Indonesia. Retrieved 04 19, 2014, from http://kemdikbud.go.id/kemdikbud/berita/2185

Nuh, M. (2014, Pebruari 26). RUU Keinsinyuran Akhirnya Disahkan DPR. Retrieved April 20, 2014, from http://pii.or.id/ruu-keinsinyuran-akhirnya-disahkan-dpr

Poerdyatmono, B. (2005). Asas Kebebasan Berkontrak (Contractvrijheid Beginselen) Dan Penyalahgunaan Keadaan. Jurnal Teknik Sipil, Volume 6 No. 1, Oktober 2005, 44 - 58.

Sianturi, M. R. (2007). Evaluasi Kesiapan Asosiasi Profesi Jasa Konstruksi dalam Mensertifikasi Tenaga Ahli Konstruksi (anggotanya), Tesis. Bandung: Program Studi Magister Teknik Sipil, Pengutamaan Manajemen dan Rekayasa Konstruksi , Institut Teknologi Bandung .

Ulfah, M. (2012). Negosiasi kepentingan sertifikasi tenaga ahli konstruksi dalam perspektif tata kelola infrastruktur. Bandung: Tesis Program Magister Studi Pembangunan, Sekolah Arsitektur, Perencanaan dan Pengembangan Kebijakan, Institut Teknologi Bandung.

Warman, Y. (2008). Kajian Evaluasi Penerapan Pasal 9 Undang-Undang Nomor 18 Tahun 1999 Tentang Jasa Konstruksi Mengenai Kewajiban Sertifikasi Bagi Tenaga Ahli Konstruksi . Bandung: Tesis, Program Studi Magister Teknik Sipil, Pengutamaan Manajemen dan Rekayasa Konstruksi , Institut Teknologi Bandung.

Widiasanti, I. (2013). Kajian Efektivitas Mekanisme Sertifikasi Tenaga Ahli Melalui Unit Sertifikasi Tenaga Kerja Lembaga Pengembangan Jasa Konstruksi. Seminar Nasional 2013 Jurusan Teknik Sipil, Fakultas Teknik, Universitas Muhammadiyah Surakarta.

Wirahadikusumah, R. D., \& Pribadi, K. (2011). Licensing Construction Workforce: Indonesia's Effort On Improving The Quality Of National Construction Industry. Engineering, Construction and Architectural Management Journal Emerald, May 2011.

Undang-undang nomor 11 tahun 2014 tentang Keinsinyuran

Peraturan Pemerintah Nomor 23 Tahun 2004 Tentang Badan Nasional Sertifikasi Profesi (BNSP) 